\title{
LOGISTICS MANAGEMENT IN DISASTER
}

\author{
DOI: 10.17261/Pressacademia.2019.1173 \\ JMML-V.6-ISS.4-2019(2)-p.212-224
}

\section{Selminaz Adiguzel}

Harran University, Siverek Applied Sciences Faculty, International Trade and Logşstics, Sanliurfa, Turkey. sadiguzel@harran.edu.tr, ORCID: 0000-0002-6808-2888

To cite this document

S. Adiguzel, S. (2019). Logistics management in disaster. Journal of Management, Marketing and Logistics (JMML), V.6(4), p.212-224.

Permemant link to this document: http://doi.org/10.17261/Pressacademia.2019.1173

Copyright: Published by PressAcademia and limited licenced re-use rights only.

\section{ABSTRACT}

Purpose- The aim of this research is to bring together studies on disaster logistics in the literature and to investigate disaster logistics management. Logistics is of paramount importance in order to prevent the loss of life and property in death injuries in an extraordinary situation. The aim of this research is to investigate logistics processes at every stage of disaster logistics.

Methodology- The qualitative research method was used in the study and the literature was reviewed and the logistic tools used in case of a disaster in the world were discussed.

Findings- Disaster scenarios are prepared for unforeseen events before and after the disaster and logistic simulations are applied and drills are performed. For urgent needs, materials such as tents, blankets, beds, heaters and kitchen sets with a long shelf life should be provided by signing protocols with suppliers. Several firms should be preferred instead of one.Personnel training is important in disaster logistics. Throughout the organization, the logistics unit personels should be distrubeted according to their talents. Plans must be proactive, before disaster, during disaster, after disaster plans should reviewed.

Conclusion- Due to the high uncertainty in terms of both supply and demand in disasters, sudden changes in the materials and materials needed in the disaster area and other such problems, the logistics unit and supply chain network must be able to overcome such negativities These requirements, which demonstrate the need for agility, require an adaptable and neatly formed flexible supply chain structure to respond quickly to changing conditions Logistics data is collected and transmitted for useare vital. Innovations in the field of logistics technology, drone, intelligent transportation systems, unmanned transportation vehicles, RFIDvs, technology-assisted disaster logistics are becoming widespread in order to save more lives in less time

Keywords: Crisis, disaster, logistics, innovation, RFID, drones. JEL Codes: H84, Q54, L91

\section{INTRODUCTION}

Disasters are man-made and /or nature-related events that adversely affect all living life in nature, cause physical, economic and social losses, and may trigger another disaster risk by disrupting the ecological system and today it continues to increase. According to the definition of AFAD, "Disaster is a natural, technological or man-made event that causes physical, economic and social losses, interrupts or interrupts normal life and human activities for all or certain segments of the society. Disasters are collected in two types natural and human disasters. In general, a disaster can be defined as "a shocking event that seriously disrupt the functioning of a community or society, by causing human, material, economic or environmental damage that cannot be handled by local agencies through standard procedures" (Jiang, and Yuan, 2018: 2). Significant advances in RFID, satellite and other related asset visibility Technologies are important for unmanned aerial vehicles, emergency responders. According to the classification of World Disaster Report, types of disasters are divided into five groups as biological, geophysical, hydrological, meteorological and climatic. Although disasters vary according to their types, the most important catastrophe affecting human life and countries is the earthquake, which is one of the geophysical disasters. EM-DAT is the Emergency Events Database at the 
Université Catholique de Louvain. It collects and compiles information on 'natural' and technological disasters from public sources. EM-DAT data doesn't include war, conflict or conflict-related famine disaster events. Natural disaster data includes: weatherrelated events (meteorological, such as storms and extreme temperatures; hydrological, such as floods, mudslides and pluvial/flash floods; and climatological, such as droughts and wildfires), geophysical events such as earthquakes, and biological events/epidemics. Data about technological disasters is not included in this analysis. (World Disaster Report, 2018). What to do in case of a disaster are: establish a network, planning, demand planning and needs identification, planning and mitigation, documentation, search and rescue, first aid and health care, fire and hazardous materials, special intervention evacuation, social services, rehabilitation, funeral procedures, agriculture services communication transport storage storage, infrastructure services debris removal temporary settlement, purchase, financing accounting financial damage detection, customs security operations external organizations coordination personnel services personnel jobs to buy.In general, disaster relief activities are distributed from the supply point of first aid supplies, food, equipment and search and rescue team to a wide range of geographically dispersed destinations in the disaster area, evacuating the victims from the disaster area, and transfer activities are related to (Barbarosoglu et al., 2002: 118). In particular, the needs of vulnerable people in need and to ensure that both products and materials and the relevant information are storage and origin point, needed for efficient streaming to the last point planning, implementation and control of activities is necessary. This constitutes disaster logistics (Thomas and Kopczak, 2005: 2) (Börühan, Ersoy, 2013:3). Management of logistics performance in the event of a disaster is called rescue operations, disaster logistics. The best definition for disaster logistics is the management of information, transport and storage of goods in a disaster area. Relief agencies and organizations involved in disaster relief activities, such as the United Nations, state that there is a serious disruption of the functioning of a society that causes widespread human, material, economic or environmental losses that exceed the capacity of those affected by a disaster (Jiang and Yuan, 2018: 2). Emergency logistics is "the support function that ensures the timely delivery of emergency resources and rescue services into the affected regions so as to assist in rescue activities. Disasters are basically divided into 5 times. These classes are; Geological disasters, Climatic disasters, Biological disasters, Social Disasters are technological disasters. According to EMDAT data, there have been 10000 disasters in the world since 1900 . The killing of 10 or more people for disaster, (The losses are also considered dead. 100 people must be affected by the disaster. Local authorities also need to declare a state of emergency. According to the EM-DAT database, drought, earthquake, epidemic, extreme temperatures, , insect infestation, slides, volcanic eruption, wild fires, wind storms, industrial accidents and transport accidents are considered as disaster (UN / ISDR, 2007; EM-DAT, 2007). The work to be done during a disaster consists of intelligence and planning, financial and administrative affairs, operations and logistics. disaster logistics plan consists of communication, transportation, storage, infrastructure services, temporary settlement services, debris removal services, external organization coordination, personnel health services.According to the Report prepared by the Research Center on Disaster Epidemiology in 2016, 345 disasters occurred in 113 countries in 2015. 22.773 people died in these natural disasters. The economic loss of $\$ 66.5$ billion affected the lives of 98 million people. Earthquakes, extreme temperatures, war, etc., cause physical and economic, environmental and cultural damages. According to the World Health Organization, natural disasters are disasters caused by natural processes or natural events. Technological, industrial or infrastructure disasters, frequent accidents due to human activities, other disasters, any natural or non-technological disasters, an example of human movements, such as refugees, are referred to as disasters. The United Nations and the World Health Organization distinguish between natural and technological disasters (UN / ISDR, 2007; IFRC, 2007). The emergency logistics service which can respond to the requests for assistance in the affected regions effectively and very quickly. (Mulyono. Ishida, 2014). Humanitarian logistics aims at the rapid gathering of people affected by the disaster and the immediate delivery of humanitarian aid. For this purpose, the logistics operation should be well planned and the deliveries must be simulated Logistics is of paramount importance in disaster relief. In the supply of basic needs of health, it is important to follow the material through the transport chain. This research's aim is review the emergency logistics, disaster logistics literature. Emergency, disaster logistics are differnt from business logistics. We taked the problem idendification and literature review and resourch the tecnology of disaster logistics in this research.

\section{LITERATURE REVIEW}

Disaster logistics, also known as humanitarian aid logistics, is designed to cover the needs of damaged and vulnerable individuals and to alleviate their suffering. .Disaster logistics; preparation, planning, procurement, transportation, storage, monitoring and control, customs clearance (Thomas and Kopzack, 2005; 2). Kunz and Reinerb (2012) stated in their meta-analysis that modeling and simulation is the most commonly used method in the studies conducted between 1993-2011. Natural events, climate change and urbanization are pushing the pressure on disaster relief operations. Decision science and ICT technologies can be effectively used to face humanitarian logistics. Comprehensive research on disaster management can be divided into 5 groups according to 
their methods: Model developed studies, literature review studies, survey method studies, interview method studies, case studies. One of the important factors in disaster logistics is to work in cooperation with charitable organizations such as AFAT Akut Kızılay. There are lots of researches on disaster logistics. The most of these researches is about models. In recent studies on disaster logistics, it is seen that the methods for model development have been emphasized and the model development method has a tendency to be used for location selection. At this point, the importance of location selection supported by quantitative methods emerges. Indeed, Peker et al. (2016), Rezaei-Malek et al. (2016), Konu (2014) and Gözaydın and Can (2013) emphasize the increasing importance of site selection in their studies. The topic (2014), in its study, underlined the importance of prepositioning humanitarian aid for a possible earthquake in Istanbul and developed a site selection model in the light of the information contained in the JICA (Japanese International Cooperation Agency) report. In this model, there are 29 demand points and 29 potential disaster response and assistance centers. Gözaydın and Can (2013:18) emphasizes that central and local centers should be established where materials, tools and equipment to be used in search and rescue, medical assistance and humanitarian activities. Those should be stored before a disaster in order to be able to be quick and effective in the response phase of disasters (Şen and Esmer 2017). Green and Kolesar, Analyzed previous or papers on urban emergency services and regular emergencies; Wright et al., extended the literature scope into homeland security such as traffic and cyber space safety in routine emergency management, but not in the context of large-scale disasters; Altay and Green III, provided disaster operations management literature classification in six dimensions. highlighted the gaps in multi-agency coordination, soft or, the use of sensing technology, recovery planning, business continuity, and management engineering. Simpson and Hancock, discussed the literature on both urban emergency service systems in early days and of large-scale disasters in 21st century. Identified a detailed literature citation network. Suggested four areas of research opportunity. Caunhye et al, reviewed optimization models in emergency logistics in the pre-disaster operations phase and post-disaster operations phase. Analyzed the literature contents in detail through the perspectives of OR models, decisions, objectives, and constraints. Galindo and Batta, extended Altay and Green's survey on disaster operations management and added analysis on most common assumptions in the field. They aimed to increase the performance of disaster relief by clustering inventory regions with their articles. They stated that logistics and inventory are the most important factors in meeting the aid requests during disaster relief. It was emphasized that the amount of inventory prepared before the disasters in the shelters was sufficient for only a short period of time and chaos could be created due to the differences in the inventory level in the shelters. Topla, 2016, p 2018) Konu, (2014), . Peker Etc (2016); Vanajakumari Etc (2016); Rezaei, Malek and Etc, (2016), , Didrichs Etc (2016), Burkart Etc (2016), Douglas, Etc (2016), Tanyaş (2013 a), Tanyaş (2013 b), Gözaydın and Can (2013), Bozorg, Amiri Et Al (2013), Afshar And Hanghani (2012), Afshar and Hanghani (2012), Lin Etc (2009), Altay Et AI (2009) researched on model development. Bealt and Etc (2016), Köseoğlu and Yıldırımşı (2015), Bastos (2014) studied on literature. Van Wessenhove And Martinez (2012), researched sample case. Bealt et al. (2016), on the other hand, emphasizes that humanitarian organizations and logistic activity providers should cooperate in the fight against disasters in the study conducted to improve humanitarian logistics. Peker et al. (2015) developed a model for determining the most suitable distribution center location in Erzincan. In this model, analytic hierarchy process (AHP) and VIKOR method are used. According to this, the most important criteria to be used in the selection of the most appropriate distribution center for Erzincan are "Iocation, infrastructure and cooperation.. Raich et al. (2014) aimed to identify the factors affecting the supply chain in disasters and to show how to optimize the performance among rescue teams in order to be better prepared for disasters. Altay et al. It has formed an integrated logistics model based on the elements of management theory. Disaster logistics; Strategic planning stage, which includes important applications such as supplier selection and communication protocols, Preparation stage where the location and quantity of the aid materials to be stored are determined Pre-incident response stage, where decisions related to the detection of an impending disaster such as hurricane What happens immediately after a disaster occurs and post-incident intervention phase. The most important phase is the strategic phase. Kovács and Spens stated that the most challenging situation in disaster logistics is coordination, and that this difficulty can be attributed to different stakeholders. Therefore, he emphasized that stakeholder theory should be applied to disaster logistics (2009: 506)( Şen and Esmer 2017,:233).,

\section{DATA AND METHODOLOGY}

\subsection{Disaster Response}

Disaster and emergency logistics consists of processes and systems that can effectively mobilize people, resources, skills and knowledge to assist victims affected by disasters (Kadıoğlu, 2011, 6). Disaster logistics; pre-disaster preparedness, disaster response process and post-response logistics activities can be evaluated in three parts. Disaster Response logistics process activities are pre-assessment and needs assessment, logistics action plan, monitoring, evaluation and reporting of the disaster 
response process. The logistics of humanitarian aid is disaster response process at emergency situations affecting people. It is called Humanitarian Logistics. Humanitarian Logistics is preparation of disaster management, intervention, improvement and reconstruction. Which is important in aid logistics; the right material, the right person, the right amount, the right quality, the right time and in the right place to transfer.

The federal government plans disaster / emergency response with two framework approaches. National Event Management System (NIMS) and National Response Framework (NRF - National Response Framework. Due to the geographical location of Japan, earthquake, tusinami, typhoon and so on. It is a country where natural disasters occur frequently. Since it is a country to be taken as an example both in precaution and in the field of education with years of experience An analysis of Japan's disaster management structure and plans is planned. Responsible for the organization and coordination mechanism for natural disasters in Japan. Disaster Prevention Council (DPC). DPC, like the US counterpart, FEMA local governments and the level of government at the national level authority is equal to the state minister. But unlike the United States, the DPC is independent of the government and directly attached to the Prime Minister Disaster management structure in the UK is centralized in contrast to the US and Japan. Logistics is of paramount importance in disaster relief. In the supply of basic needs of health, it is important to follow the material through the transport chain. Although disaster logistics processes are handled differently in the literature, this study is based on the disaster relief activity process which consists of three stages: preparation, immediate response and remediation of Kovacs and Spens (2007). The following Figure 1 presents the disaster management cycle.

Figure 1: Disaster Management Cycle

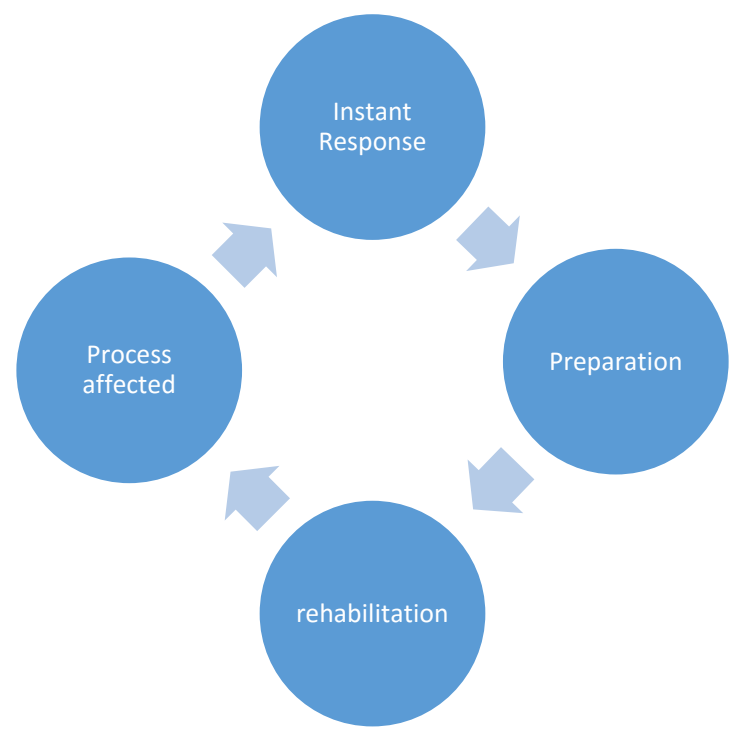

These three stages are also referred to as Disaster Management Circle. The place of logistics and supply chain in Disaster Management Circle is manifested in preparation, immediate response and improvement stages of this process. All these three stages are also described as the flow of humanitarian logistics.

Disaster and post-disaster process flow can be listed as follows:

1. Preliminary Assessment and Needs Assessment (as a result of the pre-disaster plans and preparations and the preliminary assessment at the time of the disaster, the required information, materials and human resources of the materials requested during the disaster response and assistance process are delivered to the region as soon as possible, with a regular and accurate information flow. supplied),

2. Logistics Action Plan (Determining the most appropriate transportation mode of material and human resources to the region by taking into consideration the region where the disaster occurred, likewise determining the transportation and storage of needs), 
3. Implementation of the Logistics Action Plan (shipment of existing materials, personnel and equipment to the disaster area in accordance with the itinerary plan),

4. Monitoring and Evaluation of the Response (evaluation and analysis of the disaster process by a commission that is not involved in the activities, reporting the results and storing them in case of need in the following cases).

In the digital world, each individual uses almost one smart device (phone, tablet, etc.). The available equipment of smart devices includes cameras, GPS (global positioning system) and sensors (proximity, gravity, humidity, temperature, pressure). Data can be received by these hardware in smart devices and information can be transferred to smart device users at the same time. With this data exchange, smart disaster and emergency applications to be developed can be prevented or minimized before many hazards occur. Another area that will provide data flow to smart disaster and emergency applications is smart cities. Intelligent disaster and emergency applications can be created with the data obtained from smart cities through information communication technologies. Information and communication technologies that facilitate human life are no doubt disaster and emergency Information and communication technologies that make human life easier will undoubtedly provide great benefits in disaster and emergency management. In a world where adaptation with technology is provided in all areas of life, adaptation of disaster and emergency management with technology is inevitable (Çakır, 2018, 1131).

The Istanbul Provincial Directorate of Disaster and Emergency established a radio channel called AFET FM. Citizens listening to this channel will have access to the most up-to-date information in case of a disaster. Another smart application of Disaster and Emergency Management Presidency is Earthquake Mobile application. Thanks to the earthquake mobile application, it has provided fast and reliable information about earthquakes occurring within the borders of the country and enables the earthquakes to be seen on the map (AFAD, 2017a).

Figure 2: Logistic Region Map

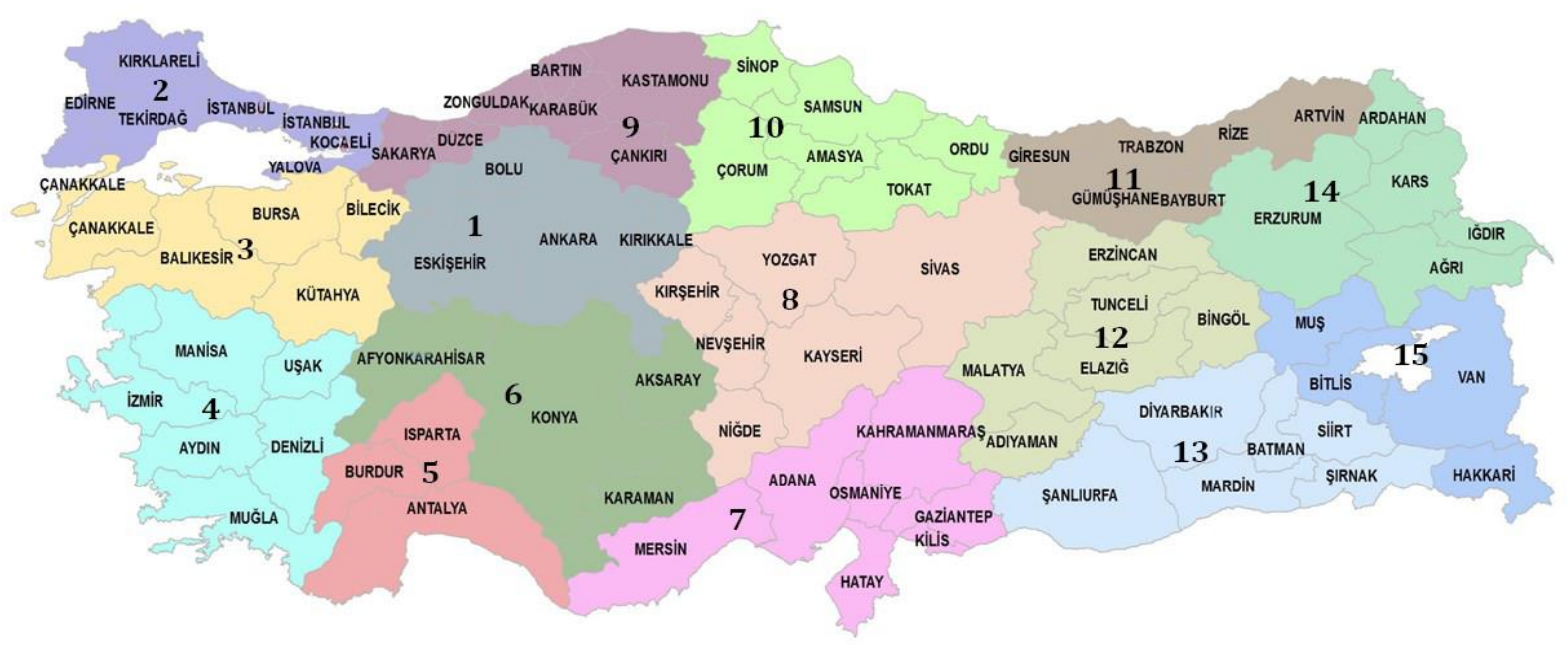

Source: AFAD, 2017 https://www.afad.gov.tr/kurumlar/afad.gov.tr/2419/files/Afet Mud PI ResmiG 20122013.pdf Acsessed Date .p 28.

AFAD organizations in Turkey, the country's authority on disaster management and disaster and emergency relief agencies and is authorized as an international organization. Identify existing resources against a possible disaster, plan, organize, prepare tool equipment and tools, develop capacity, utilize new technologies, set up, develop and test early warning systems, organize training and exercises, and need to make evaluation. Logistics and maintenance services to groups of logistics logistics services by AFAD in Turkey have been described as follows: The same donation warehouse management and distribution services, technical support and supply consists of five service groups such as international support and cooperation, and resource management. 15 regions have been established for logistics planning and cooperation Minimum 72, Maximum 120 hours "self-sufficient personnel, tools, equipment and social (shelter, nutrition, hygiene materials, etc.) and will meet the needs of the office. Any additional needs that may arise during the specified period of time or during the working period will be provided by the Service Groups Logistics Service 
Group. Therefore, each service group will make its own logistics planning in advance within the scope of disaster preparedness and build capacity if necessary

\subsection{Logistics}

The ability to calculate Logistikos in Greek is derived from the French Logistique words (to present the winter residence). The concept of logistics has been obtained by combining the concepts of calculus and logic of the soldiers' mansion. It is also mentioned in the encyclopedias that the account which consists of the combination of the words Logic and statistics means book science. According to another view, it is suggested that Logic and "Statistics birleş are formed from the merger (Russell, 2000). These words express the concept of statistical logic in Turkish terms and do not show the concept of logistics completely. The units formed by the officers responsible for the distribution and financing of the needs in ancient Greek, Roman and Byzantine civilizations were called Logistikas. The word logistics in the Oxford University Dictionary; 'Military science is defined as a branch of personnel, equipment, material handling, maintenance and provision'. Logistic services in the Ottoman Empire began with the names of derbentcilik (bridge and road maintenance and security), maritime and meremmetcilik (Wikipedia, 2012). When the disaster planning and response agencies in the world are examined, it is seen that there are central, local and mixed structures and there is not a single sample world.

\subsection{Unmanned Aerial Vehicle- UAV}

UAVs have enjoyed widespread adoption in the humanitarian sector in recent years, particularly for applications such as damage assessment and aerial monitoring.

Figure 3: Drone Logistics for Disaster Response

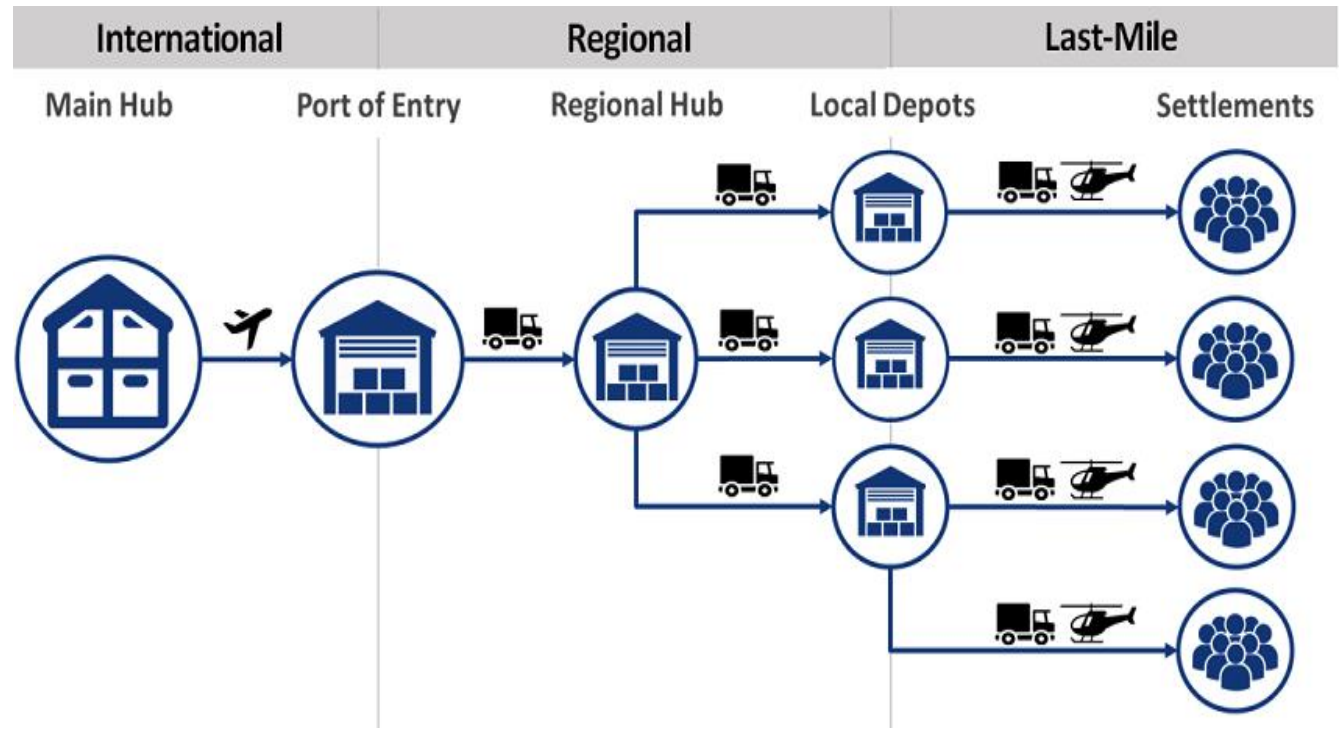

Source: https://www.tslab.org/project/drone-logistics-disasters/Acsessed Date 20.11.2019).

Recently drones, drones and disaster logistic materials were used in the unmanned aerial vehicle season. While similar to Amazon, DHL and recently UPS have been gearing up to use drones to cut costs of delivering consumer goods. A company called Zipline is applying similar technology to delivering life-saving medical supplies to difficult-to-access places ranging from less developed countries to natural or humanitarian disaster zones-and possibly even warzones (Roblin, 2019, p 1).

\section{Logistics Preparations}

Businesses need to develop effective policies in order to adapt to challenging competition conditions and to analyze their competitors' conditions and keep their conditions under control. Accurate evaluation of the competitive conditions required for 
profitability, continuity and growth, which are the objectives of the enterprise, are among the strategic objectives. Businesses provide customers with high quality, affordable goods; in the right place, at the right time (Taşkın and Durmaz, 2012: 32). Considering the fact that Turkey's earthquake zone, disaster, disaster scenarios suitable in times of crisis, it is necessary to be prepared in the transportation field. Disaster events are just like crisis events. The stages we need to address in the crisis management process are divided into five phases: 1 Determination of Early Warning Signals, 2. Preparation and Protection, 3. Limiting Loss and Loss by Controlling the Crisis, 4. Returning to Balance, 5. Learning and Evaluation. However, since the crisis caused by the earthquake is a crisis that occurs without an early warning signal, the crisis management process is different from other crisis situations. Crisis preparation includes the creation of a crisis plan, testing of the plan, training of all personnel, preparation of the crisis handbook and the creation of a crisis management team, and the establishment of a crisis management center. Before the crisis, if there is no crisis plan prepared, the situation will be twice as difficult. Difficulty and urgency will ultimately lead to numerous errors. If there is no crisis plan of a provincial / district / neighborhood established with civil defense, police, national education, police, military, prosecutor, fire department, health and municipal non-governmental organizations, the crisis plan should be prepared. The crisis plan should cover the activities before, during and after the crisis (Adıgüzel, 2000: 13). In case of a disaster, it is necessary to prepare before the disaster, to store information and materials, to establish a software infrastructure that will ensure coordination within and outside the country, to distribute the task of the team to be assigned, and to define the task. Pre-disaster sequence and post-disaster scenarios should be prepared, which means of transportation should be determined and which route to use. Disaster scenarios are written before the disaster comes to the division of labor. As speed is life-saving, the expertise of the competent persons involved in transportation is important. In order to benefit from information and communication technology, a network structure that allows access in disaster should be established. Transportation networks are strengthened through the donations of civil society organizations and volunteers. Strategic points are determined and the closest location to transportation is chosen as the center. For all modes of transport, the nearest center should be selected as the most convenient center. Earthquakes frequently occur in countries such as Tokyo and San Francisco. In countries where volcanic eruptions and hurricanes are experienced, evacuation plan logistic support plan should be prepared with proactive approach. Since all communication channels will not work when the energy infrastructure is damaged, energy supply should be provided underground in risky areas. Disasters should be informed in advance about all disasters. People in the area should be warned with warning systems.

$\checkmark \quad$ Again in the relevant regions of various warning systems

$\checkmark \quad$ Establishment of these systems with various systems.

$\checkmark \quad$ To cover the entire region

$\checkmark$ Regulation is required.

In addition, disasters can damage the energy infrastructure. In the event of a disaster, bridges can be destroyed in the country. The inadequacy of air and sea voyages due to confluence, lack of infrastructure of roads and railways, height limits in tunnels and bridges adversely affect the conditions. Therefore, according to different scenarios, alternative transportation vehicles, transportation routes and distribution channels should be determined beforehand (Wassenhove, 2006: 480-481; Altay, Prasad and Sounderpandian, 2006: 2; Kovacs and Spens, 2007: 102). In the post-disaster phase, basic needs, medical equipment become an important part of disaster logistics. Therefore, a disaster plan should be prepared in accordance with various scenarios by considering all kinds of situations. Job descriptions should be prepared as contracts and legal documents should be made in advance with the suppliers who will supply the hospital and other materials. In the scenario, which stores will be used in inventory management and storage should be included.

Periodic maintenance of stocking disaster material, determination of transportation capacity and contracting of transportation companies to be worked on, road maps should be determined. Lack of communication with suppliers during the operations of the local and regional partners of the relief agencies may cost the lives of the victims. Disaster relief activities in preparation phase. Aid organizations that are in charge of the project may set up collaborative platforms such as the United Nations Joint Logistics Center (UNJLC) or the Disaster Relief Network operated by the World Economic Forum. It can provide partnerships with the United Nations for use in humanitarian operations (Kaatrud et al. 2003,13). The selection of experts in disaster management is important. Disaster management, unlike other business management crises, the intervention affects the country or a part of the country, and thousands of people need emergency at the same time. All processes of management, planning, organizing, coordinating, communication, ordering, supervising / evaluation etc. are also important in disaster management. The most important situation that emerges after the disasters is the lack of coordinated cooperation and plans against disasters (McClintock 2005, Murray 2005, 
Sowinski 2003). Knowledge management: Obtained from disasters a database created by sharing experiences and information for effective disaster management It provides. Logistic activities should be at the center of the preparatory phase. Financial resources enough money, help to provide financial resources such as the fund and to effectively distribute it to the region of need.

Cooperate throughout the process by making agreements with communities that will ensure unity in all these challenging processes, such as government, military enterprises, or other charitable organizations. Inventory locations should be shown in the plan, and who should work in the inventory and warehouses should be specified in the job descriptions. The warehouse should be close to the center, the products should be packaged and kept in cold conditions. It is necessary to determine the officers of the warehouse transfer vehicles, to specify the places where the vehicles will go, to determine where the fuels to be put in the vehicles will be taken and the way the payments will be paid. It is also important to make a financial plan for the unexpected costs and how they will be paid.

Disaster logistics is important at this point. Disaster logistics is described as efficient and cost effective flow, storage, planning, implementation and control of goods, merchandise and related information from the first production point to the end consumption points in order to satisfy the needs of the people. Stages of disaster logistics are pre-disaster preparedness, disaster response process and post intervention logistics activities. Disaster logistics must be event-based and dynamic. Due to every disaster have its own features as the type, severity, according to temporal and geographic features and the sensitivities, disaster logistics is an issue that a constantly working area and requires the development of new approaches. Therefore, the continuous measurement of risk and disaster management plan always needs revision ( Işıktekin, 2015, 1).

The requested purchased materials must be safely transferred at the right place at the right time at minimum cost. Who will provide logistics support, where warehouses will be installed, where waiting areas will be established, the cost of the warehouse is calculated, four indicator models for Disaster logistics developed by Davidson (2006) are based on commercial and military performance measurement principles. The indicator set used in disaster logistics includes the following four items:

The scope of the appeal, which is intended to show how well the organization has responded to the appeal, is an operation in finding donors and providing products. There are two special precautions. Recommended: (1) Scope of appeal = pledged items / required items, (2) $2 \%$ of delivered goods $=$ (products $/$ items delivered on site) $* 100 \%$.

1. Donation-delivery-time is a measure of how long it takes to deliver a product. Once a donor has promised to make a donation, he is delivered to the country of destination. This is measured by either (1) the average number of days or (2) the median number of days.

2. Financial efficiency intended to include the financial aspect of providing assistance. Three metrics were proposed:

(1) relative metric $=($ Actual cost - budgeted cost $) /$ budgeted cost,

(2) absolute metric = actual cost - budget cost, (3) shipping cost $=$ shipping cost $/$ total amount.

3. The accuracy of the assessment is to indicate how much the final budget of the operation is.

4. This does not only include financial changes,

National and local government, through which humanitarian organizations must often coordinate their activities, may be severely impacted, or even uprooted in the case of a conflict situation. Preparing disaster scenarios and performing exercises of these scenarios such as tunnels, roads, bridges, overpasses in the event of earthquakes in the event of panic, security problem, measurement of disaster risk, disaster logistics support operational planning should be done.

The effectiveness of a disaster scenario is measured during the exercise. A logistics support plan should be prepared for this. The most important logistics activities are rescue activities and transporting like food and beverage fundamental human needs. Each country should prepare a logistic plan according to its structure. Turkey, terrain, due to the negativity of landforms and meteorological conditions are often faced with major natural disasters. Natural disasters cause significant wounds in the economic and social structure of our country. Rapid population growth and unplanned urbanization increase natural disaster losses https://www.istka.org.tr/media/24626/\%C4\%B0stanbul-\%C4\%B0li-afet-loger-plan\%C4\%B1-k\%C4\% B1 Guide.pdf (Accessed on 12.10.2019). In order to develop disaster logistics, it is necessary to examine the studies conducted in the literature and apply these studies. 


\section{FINDINGS AND DISCUSSIONS}

Emergency scenarios of logisctics are strongly affected by uncertainty. The uncertainty is in the relief request esources and equipment provided by public and private actors, uncertaintyin the conditions of the connecting network. At this aim both optimization and simulation approaches must address uncertainty for emergency logistics.

In the modern disaster management concept, pre-disaster prevention activities such as mitigation of losses and losses, preparation, prediction and early warning, and understanding of disasters are considered as "Risk Management"; post-disaster studies such as impact analysis, intervention, improvement and restructuring are considered as "Crisis Management ((Kadıoglu, 2008).

\section{Graffic 1: Disaster Managment System}

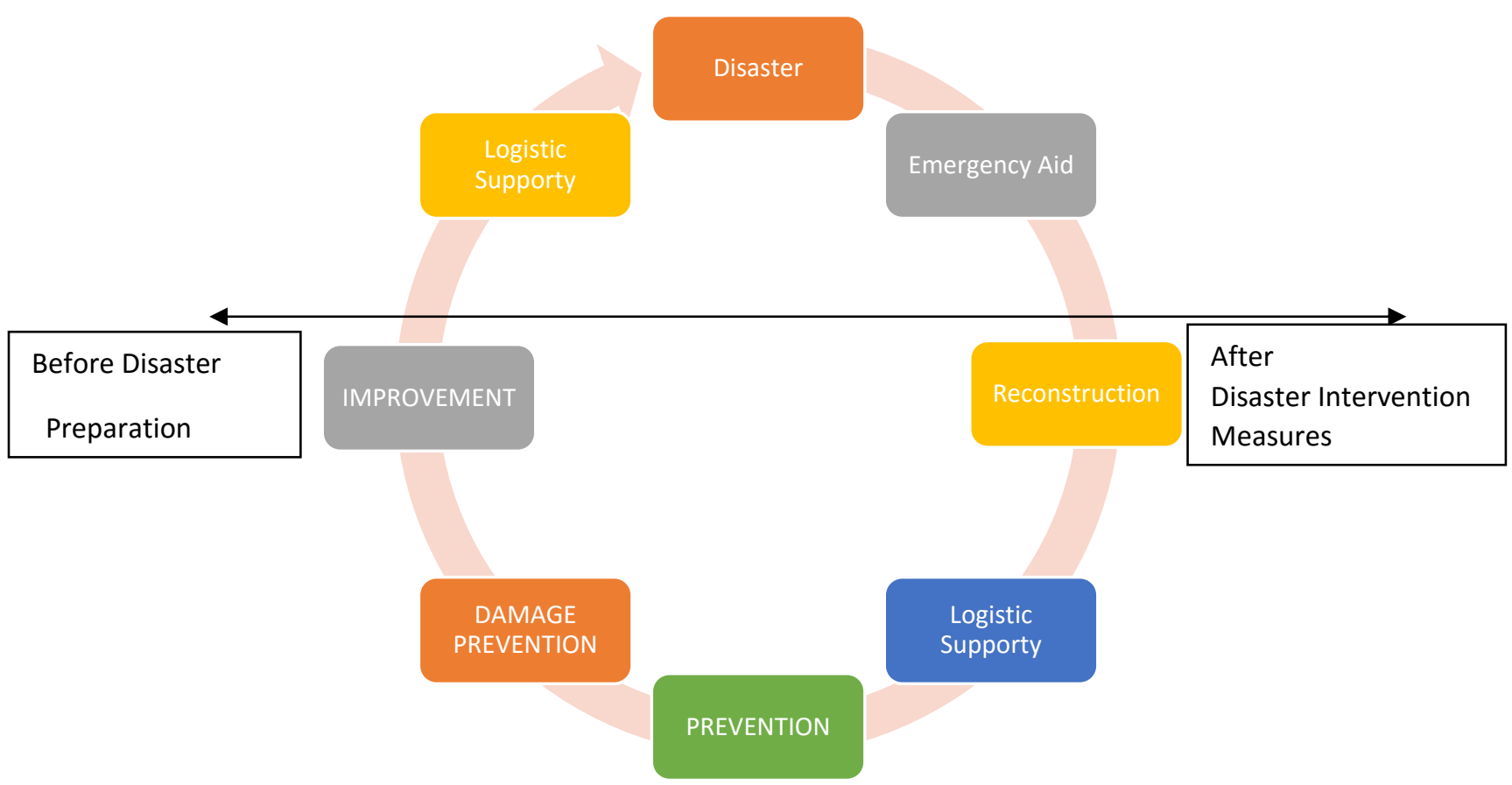

In this context effective disaster management, pre-disaster, disaster and post-disaster studies (Demirci and Karakuyu, 2004). The disaster plan should include the following stages before and after the disaster: Emergency Aid, the Reconstruction, logistic Supporty, prevention, damage prevention, improvement, logistic supporty.

Logistics efforts, as follows:

Assessment: At the time that a disaster, logistics supports must to be quick and accurate. Hence, team with individual expertise usually arrive area within the first 24 hours of a crisis.

Appeals Management: A preliminary appeal for donations of cash and relief supplies is launched oftenwithin 36 hours of the onset of the disaster.

$\begin{array}{ll}- & \text { Assessment } \\ \text { - } & \text { Appeals Management } \\ \text { - } & \text { Operations Planning } \\ & \text { Mobilization }\end{array}$




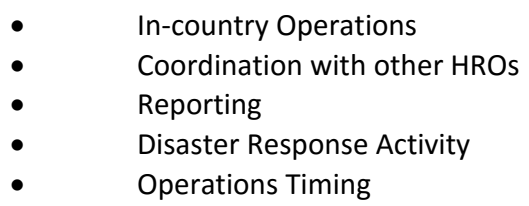

Mobilization: International transport capacity is mobilized and supplies are sent directly to the afflicted country, where relief aid must clear customs and then be transported by local transport to warehouses nearest the disaster site. http://www.fritzinstitute.org/PDFs/WhitePaper/EnablingDisasterResponse.pdf Acsessed Date 10.15..2019).

\subsection{Transportation Mode}

In case of the disaster, the mode of transportation to the disaster area should be determined and the companies that will provide access to the storage center should be contracted. In order to use a region as a disaster management area, preparation of a disaster plan scenario (material, tools, materials and processes), determination of the usage permission, contract, distribution centers, warehouse areas of the region (material, tools, equipment and processes), creation of external storage conditions, List of the aids at the customs gate points should be listed, created, and the scenario of the transport operations should be written, in which mode of transport the aid will come. The reliability, reference and business portfolio of subcontractors in the supply of disaster materials should be examined. Care should be taken to store and stack to prevent waste of material. For urgent needs, materials such as tents, blankets, beds, heaters and kitchen sets with a long shelf life should be provided by signing protocols with suppliers. Several firms should be preferred instead of one. . In case of disaster, the standard of the material to be taken should be determined in advance, how many of each material will be, the characteristics and the standard.

\subsection{Transportation Management}

In disaster logistics, logistics management infrastructure should be established in order to transport the materials to be transported in the scenario in the right place, at the right time, in the right way, with minimum cost and safely. The transport mode must be selected according to the material. For this purpose; Vehicle types (frigofric, container carrier, closed body, etc.) and capacities related to different material types should be determined, which way to use in the disaster situation, who is responsible for loading and unloading, the first degree loading and unloading methods in disaster should be determined. The vehicle tracking system should be created according to the computer network on which the vehicle goes where it should be monitored (GPS, GPRS, GIS). Transport management information technology (TMS). , maintenance of vehicles, training of personnel using the vehicles, the penalties they receive, and the inspection of the vehicle should be followed. Material delivery and delivery of materials from vehicles should be established. Considering that even the aid vehicles could not enter the city due to traffic congestion in the 1999 Earthquake; digital routing signs, which will be located at the main junction points in the city and can be integrated with smart transportation systems, will be able to direct the citizens to the roads with less traffic in order to prevent traffic congestion in case of a disaster. Thanks to these signs, which can be controlled centrally by the provincial disaster and emergency directorates, the traffic on the main roads leading to the disaster site can be sent to the side roads (Çakır, 2018, $p$ 1135). Thanks to intelligent transportation systems, traffic lights can be remotely controlled and directed to meeting centers. Considering that the telephones cannot be used in case of disaster, wireless communication network should be established in logistics management.

\subsection{Warehouse Management}

Warehouse Management, one of the most important issues to be considered when designing warehouses should be in a way that will allow for development when capacity increase is made in the future within the framework of increasing risk (Tanyaş, 2012). Logistics management includes storage. Warehouse location should be easy to access in the right direction in the right area, the size of the land should be appropriate. In order to provide food aid in disaster, it is inevitable to stock up basic materials and keep them ready. Minimum requirements for proper storage service; the depot warehouses should be treated as regional and local distribution centers. Inventory management system should be dry. Periodic tank counting should be done to eliminate deficiencies. Storage area to be used for disaster should be close to the center, storage should be provided in accordance with climatic conditions, a separate stock card should be opened for each material and stock code should be given to all the materials 
defined in the content. The warehouse management center is equipped with a loading and unloading system (barcode, FRID, WMS, etc.) infrastructure, camera system, lighting warehouse management information board, equipped with a loading and unloading system, periodic. Reporting in order to control, monitor and trace the materials stored in the warehouse, periodic reporting should be made. All processes and material inputs and outputs made to the support process in the logistics process and operations should be reported. In the light of the data obtained from the prepared reports; Defects should be identified. Natural disasters such as earthquakes, tsunamis, tornadoes, chemical explosions, etc. are a part of life and many countries around the world share this fate. According to United Nations Disaster Assessment and Coordination Team, 2006: 1). Disaster logistics is the planning, implementation and management of the efficient and cost effective flow and storage of aid materials and the necessary information from the production points to the disaster areas where they will be consumed. Disaster logistics functions include preparation, supply, transportation, tracking, storage, inventory management and customs operations (Köseoğlu, 2011: 2). Firstaid in an emergency transportation of materials, communication equipment, repair materials and electrical power required for water supply, and transportation of food, temporary shelters and officials to the required places. Disaster logistics operations require the inclusion of a diverse number of independent NGOs and governments, as well as the use of different modes of transport. Such operations are hampered by logistical bottlenecks and managerial reasons due to lack of infrastructure in the receiving region (Oloruntoba et al., 2006:116). Humanitarian operations require the supply, storage and distribution of basic aid materials to those in need. Humanitarian aid logistics information systems; throughout the organization, the logistics units are integrated into the wider human supply chains and the development of logistics activities (Köseoğlu, 2015, 20).

\section{CONCLUSION}

In the event of a sudden disaster, a logistics plan should be prepared for the delivery of health services, basic aid, rescue, first aid and reconstruction of the living areas after the disaster. Since technological innovations are life-saving in intervening people competing over time, drones with unmanned aerial vehicles, remote controlled, semi-automatic or fully automatic flight capability should be used. Small, medium and large-scale monitoring receiving images from various angles, including various sensors such as cameras, laser scanners, navigation and inertial sensors; it sends. In disaster response, effective communication, information sharing and informed decision making play an important role in disaster logistics in order to determine transport capacity? Modern technology also shows itself in the field of logistics to save human life. Since the technology used in the disaster is of great importance in saving human life in a sudden heart attack, how effective the depibrillator is for cardiac massage, state managers have technological tools and personnel who know how to use these tools in disaster preparedness and whether the plan is suitable for this area with continuous training exercises need to be done. With the integration of geographical positioning systems such as (GPS) and unmanned aerial vehicles systems, many rescue and evacuation operations will be carried out in hazardous environments after the disaster victims of search and rescue activities are found. Since the structure of the disaster area will endanger the safety of those going to rescue, carrying out inspection, thermal scanning and laser scanning operations should be carried out. The conditions and capacities of the airlines, ports, railways and highways should be determined, the storage facilities and capacities of the organization beyond its own means. it should be a place where it can be done easily, regional Warehouses (Post-intervention service, distribution warehouses), Local Warehouses (First Response warehouses, small scale warehouses) should be prepared, refrigerated carriers should be available, transportation with sufficient vehicle fleet, shipment will be provided in the fastest and safest way, informing team officials and Crisis Management Center monitoring, evaluating and ultimately reporting comprehensive activities by the team planning should be implemented.

\section{REFERENCES}

ABIS (2017). ABIS Map View. http: /webgis.umraniye.bel.tr/keos/map5aspx?workspacen = The AFETHRT6Acsessed Date 20.11.2019. Accessed 10.08.2017.

Adiguzel S, (2007), Qualifications of Primary School Principals on Earthquake-Related Crisis Management, Yildiz Technical University Institute of Social Sciences Educational Management, Supervision, Master Thesis in Planning and Economics.

AFAD (2017a). Disaster and Emergency Management (Earthquake Department) Latest Earthquakes, Access Date 30.07.2017, https://deprem.afad.gov.tr/sondepremler.Acsessed Date 20.11.2019

AFAD, (2017b). Uninterrupted and Secure Communication System, Access Date 14.09.2017, https: //www.afad.gov.tr/en/3558/Uninterruptedand-SecureCommunication -System-Project-KGHS. Acsessed Date 20.11.2019 
AFAD, (2017). Individual Mobile Device Application for Disaster Management, Istanbul Governorship Provincial Directorate of Disaster and Emergency, Access Date 30.08.2017,

Ahimbisibwe A., Ssebulime R, R Tumuhairwe and W Tusiime, (2016), Supply Chain Visibility, Supply Chain Velocity, Purchasing and Supply Chain Alignment And Humanitarian Supply Chain Relief Agility Department of Procurement and Logistics Management, European Journal of Logistics, Faculty of Computing and Management Science, Makerere University Business School, European Centre for Research Training and Development Vol.4, No.2, Po box 1337 Kampala, Uganda.

Altay, N., Prasad S., Sounderpandian J., (2006). "Strategic Planning for International Disaster Relief Logistics: Implications for Research and Practice", International Journal of Services Sciences, Vol 2, No: 2.

Antonio D'Uffizi, Marco Simonetti, Giuseppe SteccaGiuseppe Confessore, (2014), A Simulation study of logistics for disaster relief operations, 9th CIRP Conference on Intelligent Computation in Manufacturing Engineering, Scicience Director.

Atalay, B, (2015), Disaster Logistics, Journal of Osmangazi Medicine, Humanitarian Logistics. 37 (3).

Altay, N. And Green, W. G. (2006). OR/MS research in disaster operations management. European Journal of Operational Research, Vol. 175 No. 1, pp. 475-93.

Balcik, B.and Beamon, B.M. (2008). Facility location in humanitarian relief. International Journal of Logistics: Research and Applications, Vol. 11 No. 2, pp. 101-21.

Balcik,B., Beamon, B.M. and Smilowitz, K. (2008). Last mile distribution in humanitarian relief. Journal of Intelligent Transportation Systems, Vol. 12 No. 2, pp. 51-63.

Barbarosoglu,G., Ozdamar,L. And Cevik, A. (2002). An interactive approach for hierarchical analysis of helicopter logistics in disaster relief operations. European Journal of Operational Research, Vol. 140 No. 1, pp. 118-33.

Barbarosoğlu, G. Özdamar, L. Çevik (2002). An interactive approach for hierarchic analysis of Helicopter Logistics in Disaster Relief Operations. Europen Journal of Operational Research, Vol 1490 number 1.

Börühan, G., Ersoy, P., and Tek, Ö. B. (2012). Preliminary Importance of Logistics Planning and Checklist Method in Disaster Management. "National Logistics and Supply Chain Congress, Konya University. National Logistics and Supply Chain Congress.

Ersoy P, (2013). The Importance of Disaster Logistics in Terms of Logistics Processes, Yasar University.

Flood, E. and Durmaz, Y. (2012). Logistics Activities. Ankara: Details Publishing.

Gözaydın, O. and Can, T. (2013). Selection for Logistics Center of Earthquake Aid Stations: The Case of Turkey. Journal of Aeronautics and Space Technologies / Aeronautics and Space Technology Magazine, 6 (2).

Gündoğan T, (2017), A Literature Review on the Applicability of Agility Philosophy in Disaster Supply Chains, Proceedings of the International Congress of Social Sciences in the Balkans, Sakarya University.

Kadıoğlu, M., (2011). Disaster Management Expecting the Unexpected, Managing the Worst. T.C. Marmara Municipalities Union Publication: Istanbul.

Kovács, G., and Spens, K. M. (2007). Journal Humanitarian Logistics in Disaster Relief Operations. International Journal of Physical Distribution and Logistics Management. 37 (2). http://dx.doi.org/10.1108/09600030710734820.

Kovács, G., and Spens, K. M. (2011). Humanitarian Logistics and Supply Chain Management: The Start of a New Journal. Journal of Humanitarian Logistics and Supply Chain Management. 1 (1): 5-14. http://dx.doi.org/10.1108/20426741111123041

Kovács, G., and Spens, K. M. (2011). Gap Trends and Developments in Humanitarian Logistics - A Gap Analysis. International Journal of Physical Distribution and Logistics Management. 41 (1): 32-45.

Kunz, N., and Reiner, G. (2012). A Meta-Analysis of Humanitarian Logistics Research. Journal of Humanitarian Logistics and Supply Chain Management. 2 (2): 116-147.

Köseoğlu, A. M. (2015). Afet Yönetimi ve İnsani Yardım, Nobel Yayınevi, Ankara.

Murat A, 2016, Political Effects of Disaster Management Problems Related to Disaster Logistics, ISEM 3rd International Symposium on Environment and Morality, 4-6 November 2016, Alanya - Turkey.

N. B Mulyono And Yoshiteru, Humanitarian, (2014), Logistics And Inventory Model Based on Probabilistic Cellular Automata, Ishida International Journal of Innovative Computing, Information and Control ICIC International, Volume 10, Number 1, February. 
Önsüz M F, Disaster Logistics, Eskişehir Osmangazi University, Faculty of Medicine, Department of Public Health, https://dergipark.org.tr/en/download/article-file/190605

Pektas T., (2012), District Disaster Logistics: Basaksehir Application Bah, Bahcesehir University, SBE Master Thesis, Istanbul.

Roblin S, 2019, Will Blood-Bearing Delivery Drones Transform Disaster Relief and Battlefield Medicine? https://www.forbes.com/sites/sebastienroblin/2019/10/22/will-blood-bearing-delivery-drones--transform-disaster-relief-and-battlefieldmedicine/\#6d8ec8562523. Acsessed Date 12.08.2019.

Sen G, Soner Esmer, (2017), Disaster Logistics: A Literature Survey, Year 5 - Number 5 / Special Issue 23. Acsessed Date 10.11.2019

Şen and Esmer 2017, Afet Lojistiği: Bir Literatür Taraması https://www.researchgate.net/project/afet-lojıstıgı-bır-lıteratuer-taraması

Tanyaş, M., Günalay, Y., Aksoy, L., and Küçük, B. (2013a). Yeni New Model Proposal for Rize in Disaster Logistics Management. Proceedings Book. II. Rize Development Symposium, Recep Tayyip Erdoğan University.

Tanyaş, M., Günalay, Y., Aksoy, L., and Küçük, B. (2013b). Bir A Study on Logistics Management after Possible Earthquake in Istanbul. 2ndNational Logistics and Supply Chain Congress, 16-18 May Aksaray.

Taşkin E, Durmaz Y, (2010). The Role of Service Quality of the Logistic Activities in Creating Customer Value and a Research on the Institutional Customers of Yurtiçi Cargo. European Journal of Economics, Finance and Administrative Sciences (Yayın No: 333059)

Tenth Development Plan 2014-2018: Effectiveness in Disaster Management T. C. Ministry of Development Specialized Commission Report. Ministry of Development Publications, Ankara.

Thomas, Anisya S. And Laura R. Kopczak; (2005). From Logistics to Supply Chain Management: The Path Forward in the Humanitarian Sector. Fritz Institute. http://www.fritzinstitute.org/PDFs/WhitePaper/FromLogisticsto.pdf, 26/03/2017.

UN/ISDR, IFRC, (2007). International Day for Disaster Reduction. https://www.unisdr.org/2007/campaign/iddr/2007-iddr-activitiese.htmlAcsessed Date.11.20.2019.

Yaman, M, ve Çakir, E (2018). Dijitalleşen Dünyada Akıllı Afet ve Acil Durum Uygulamaları. Itobiad: Journal of the Human and Social Science Researches 7.2.

Yiping Jiang and Yufei Yuan, (2019), Emergency Logistics in a Large-Scale Disaster Context: Achievements and Challenges. International J Environ Res Public Health. 16(5): 779.

World Disaster Report, https://www.researchgate.net/publication/284285042Acsessed Date 10.11.2019.

https://reader.elsevier.com/reader/sd/pii/S2212827115006721 Acsessed Date 11.20.2019.

https://www.researchgate.net/publication/322223920_AFET_LOJISTIGI_BIR_LITERATUR_TARAMASI Accessed Date 10072019

https://www.istka.org.tr/media/24626/\%C4\%BOstanbul-\%C4\%BOli-afet-loger-plan\%C4\%B1-k\%C4\% Accessed Date 12.10.2019

https://www.tslab.org/project/drone-logistics-disasters/Acsessed Date 20.11.2019).

http://afadist.istanbulafad.gov.tr/. Acsessed Date 20.11.2019 